\title{
Effect of Curcumin on Oxidative Stress in a Model of Turpentine Induced Acute Experimental Inflammation
}

\author{
Andrei CONEAC ${ }^{1}$, Meda S. ORĂSAN ${ }^{2 *}$, Daniel C. LEUCUȚ $\breve{A}^{3}$, \\ Nicoleta DECEA ${ }^{4}$, Miuța FILIP ${ }^{5}$, Carmen M. MIHU ${ }^{1}$, Adriana MUREȘAN ${ }^{4}$, \\ Remus I. ORĂSAN ${ }^{4}$, Mărioara MOLDOVAN ${ }^{5}$
}

\author{
I "Iuliu Hațieganu" University of Medicine and Pharmacy, Histology Department, 8 Victor Babeș Street, \\ 400012Cluj-Napoca,Romania; coneac.andrei@umfcluj.ro; carmenmihu@umfcluj.ro \\ 2"Iuliu Hațieganu" University of Medicine and Pharmacy, Physiopathology Department, 8 Victor Babeș Street, \\ 400012 Cluj-Napoca, Romania; orasan.meda@umfcluj.ro (*corresponding author) \\ 3"Iuliu Hațieganu" University of Medicine and Pharmacy, Department of Medical Informatics and Biostatistics, 8 Victor Babeș Street, \\ 400012Cluj-Napoca,Romania; dleucuta@umfcluj.com \\ 4"Iuliu Hațieganu" University of Medicine and Pharmacy, Physiology Department, 8 Victor Babeș Street, \\ 400012Cluj-Napoca, Romania; nicoleta_decea@yahoo.com;muresanadriana@yahoo.com; rorasan@yahoo.com \\ s"Babeş-Bolyai" University, Raluca Ripan Institute for Research in Chemistry, 30 Fântânele Street, \\ 400294Cluj-Napoca, Romania; filip_miuta@yahoo.com;mmarioara2004@yahoo.com
}

\begin{abstract}
Curcumin, a natural phenolic compound is an anti-tumor agent with anti-inflammatory and anti-oxidant properties. The aim of this research was to evaluate oxidative stress levels, the antioxidant activity and Curcumin concentrations by high performance liquid chromatography (HPLC) in an acute experimental inflammation induced by Turpentine oil (intramuscular $0.6 \mathrm{mg} \mathrm{kg}^{-1}$ body weight) and to compare a prophylactic versus a therapeutic regimen of Curcumin (oral suspension of $150 \mathrm{mg}$ Curcumin $\mathrm{kg}^{-1}$ rat weight). Sixteen adult male Wistar rats were assigned to four groups: Control, Group I (Curcumin only), Group II (Curcumin administration, then induced inflammation after 1 hour) and Group III (induced inflammation then Curcumin administration after 2 hours). Oxidative stress was assessed by measuring serum malondialdehide and carbonylated proteins, while systemic and local total antioxidant capacity was determined by ABTS. Local tissue changes (muscle, kidney, liver) were analysed using histopathology. Results showed that acute inflammation significantly increased lipid peroxidation in Groups II and III compared to Control and Group I. A significantly reduced total antioxidant capacity (ATBS) was present in serum and kidney in Group II, also in muscle and kidney in Group III. ABTS levels were significantly increased only in the liver tissue of the animals in Groups II and III with induced inflammation as compared to Group I. This study proved the potential of Curcumin in reducing oxidative stress in both prophylactic and therapeutic regimens.
\end{abstract}

Keywords: acute inflammation, antioxidant capacity, Curcumin, oxidative stress, Turpentine

\section{Introduction}

Acute inflammation represents the initial response of the body to harmful agents and consists of the delivery of host defence mediators (leukocytes and plasma proteins) from the blood in the injured tissues. In acute inflammation, vascular changes in flow and calibre begin early after injury and come along with cellular modifications (increase in number and activity). The initial reflex vasoconstriction is followed by vasodilation (induced by histamine, kinin and prostaglandins) with validation of inflammation signs: hyperaemia, erythema and increased local temperature (Mitchell, 2013; Malay et al., 2016).

Vascular permeability increase supports inflammatory exudate emission and local oedema (Parakrama and Clive, 2005; Porth, 2007). The vascular leakage mechanism represents an immediate transient response in the venules (reversible and short lived, 15 to 30 minutes) due to histamine, bradykinin, leukotrienes, the neuropeptide substance $\mathrm{P}$ and other chemical mediators. In contrast to histamine effect, cytokines (interleukin-1, tumour necrosis factor, interferon gamma) also increase vascular permeability, in a delayed ( 4 to 6 hours) and long-lived mechanism (more than 24 hours). A 
66

delayed prolonged leakage, caused by the direct effect of endothelial cell damage of the injurious agent, involves both the venules and the capillaries, starting from 2 to 12 hours post injury and lasting for hours, even days (Mitchell, 2013).

The loss of fluid causes an increase of erythrocyte concentration in small vessels, enhanced blood viscosity with platelet adhesion and aggregation that which slow down blood flow. All these modifications lead to local stasis, which may become apparent at 15 to 30 minutes after injury. Stasis causes endothelial lesions and metabolic disorders, micro thrombi formation and leukocyte adhesion to vascular endothelium via adhesion molecules expressed by endothelial cells (P, E-selectin, or ICAM) or leukocytes (L-selectin, integrins) which occur within 1 to 2 hours (Montiel-Duarte et al., 2004; Ewing et al., 2007). In the first 6 to 24 hours, neutrophils predominate in the inflammatory infiltrate, then are replaced by monocytes in 24 to 48 hours (Mitchell, 2013).

The cellular inflammatory infiltrate is represented by neutrophils and macrophages that are attracted to the inflammatory focus by chemotactic factors, bacterial toxins, anaphylatoxins, leukotrienes and interleukins (Sermon, 2008). Leukocytes roll along the endothelial surface and cross the capillary wall to reach the interstitial space. Phagocytosis is achieved by engulfing foreign particles with the production of phagolysosomes and the digestion of particles by means of oxidative mechanisms (increased oxygen consumption, glycogenolysis, glucose oxidation and production of reactive oxygen species) or non-oxidative mechanisms (lysozyme, lactoferrin) (Serhan and Savill, 2005). Reactive oxygen species (ROS) are chemically reactive molecules containing oxygen, that due to environmental stress and biochemical factors can increase dramatically and lead to cell toxicity, damage of the molecular membrane, aging and death (Perez and Brown, 2014; Jagannathan et al., 2016).

Several metabolic changes occur in the inflammatory area triggered by vascular stasis and cellular hypoxia: local accumulation of lactic acid, arachidonic acid and lysosome enzymes released from phagocytes, inflammatory oedema and intensified protein catabolism (Deguci, 2015).

A natural phenolic compound, Curcumin, is reported to be an anti-tumour agent with anti-inflammatory and anti-oxidant properties (Goes et al., 2008). Several studies have shown that Curcumin is eight times more powerful than vitamin $\mathrm{E}$ in preventing lipid peroxidation, as marker of oxidative stress (Boyanapalli and Tony Kong, 2015). In addition to its chemotherapeutic activity, Curcumin has also been cited as a potential chemopreventive agent (Hsu and Cheng, 2007). It is thought to induce apoptosis in cancer cells and to inhibit phorbol ester-induced protein kinase C (PKC) activity. It also inhibits the production of inflammatory cytokines by peripheral blood monocytes and alveolar macrophages (Anand et al., 2007). Curcumin is a potent inhibitor of EGFR tyrosine kinase and I $\mathrm{I} B$ kinase and inhibits nitric oxide synthase (iNOS), cyclooxygenase and lipoxygenase. It easily penetrates into the cell cytoplasm accumulating in membranous structures such as the plasma membrane, endoplasmic reticulum and nuclear envelope (Gupta et al., 2013; Aggarwall et al., 2007).

Our study aimed to evaluate the serum level of oxidative stress (by malondialdehyde and carbonylated proteins assessment) and antioxidant capacity (by ABTS testing) of Curcumin administration on rats $\left(150 \mathrm{mg}\right.$ Curcumin $\mathrm{kg}^{-1}$ rat weight, as oral suspension) in an acute experimental inflammation induced by Turpentine oil (i.m. $0.6 \mathrm{mg} \mathrm{kg}^{-1}$ body weight). A prophylactic administration (first Curcumin administration then induced inflammation after 1 hour) versus a therapeutic regimen (induced acute inflammation followed by Curcumin administration after 2 hours) were compared. Local tissue changes (muscle, kidney, liver) were assessed by histopathological examination. Curcumin concentration was determined by HPLC analysis.

\section{Materials and Methods}

\section{Chemicals}

Curcumin (1E.6E)-1,7-bis(4-hydroxy-3-methoxyphenyl) hepta-1,6-diene-3,5-dione, purity > 98\%) and Carboxymethyl cellulose (CMC) were purchased from Abcam (Cambridge, United Kingdom). Turpentine oil was bought from Acem (Argelato, Italy). Methanol and formic acid were purchased from Merck KGaA (Darmstadt, Germany). Analytical grade water and $0.45 \mu \mathrm{m}$ PTFE filters Syringe were obtained from Millipore (Milford, MA, USA). All reagents used in this study were of analytical grade and commercially available.

\section{Equipment}

The employed high performance liquid chromatography (HPLC) system (Jasco Chromatograph, Japan) was equipped with: an intelligent HPLC pump (Model PU-980), a ternary gradient unit (Model LG-980-02), an intelligent column thermostat (Model CO-2060 Plus), a UV detector (Model UV975) and an injection valve equipped with a $20 \mu \mathrm{L}$ sample loop (Rheodyne). It was controlled by ChromPass software. Separation was carried out on a Lichrosorb RP-C18 column (25 x $0.46 \mathrm{~cm}$ ) from Merck KGaA (Darmstadt, Germany). Conventional light microscopy (Leica DMD 108 microscope equipped with Leica digital camera and software) was used for histopathological assessment.

\section{Chromatography}

The mobile phase was a mixture of methanol and $0.1 \%$ formic acid $\left(90: 10, \mathrm{w}^{-1}\right)$. For HPLC analysis, each sample of 200 $\mu \mathrm{L}$ rat plasma received $800 \mu \mathrm{L}$ of methanol and it was shaken for three minutes in order to precipitate the plasma proteins. The mobile phase and samples were filtered through a $0.45 \mu \mathrm{m}$ membrane and degassed prior to use. A flow rate of $1.2 \mathrm{~mL} \mathrm{~min}^{-1}$ was used. All chromatographic procedures were conducted at $30^{\circ} \mathrm{C}$ column temperature. The samples were injected manually with a Hamilton Rheodyne Syringe $(50 \mathrm{~mL})$ into the HPLC system. The UV detection was performed at $425 \mathrm{~nm}$. Three HPLC determinations were performed for each sample and the mean value was calculated individually for the time-frame intervals.

\section{Standardsolutions and spikedsamples}

The stock solution of Curcumin was prepared in methanol at a concentration of $100 \mathrm{mg} \mathrm{mL}^{-1}$ and stored at a temperature of $4^{\circ} \mathrm{C}$ in amber coloured bottle. The Curcumin stock solution was diluted with methanol to obtain working solutions of concentrations ranging from 1 to $20 \mu \mathrm{g} \mathrm{mL} L^{-1}$, which were stored in tightly capped amber-coloured volumetric flasks. Standard solutions $\left(0.1,0.2,0.5,1,2 \mu \mathrm{g} \mathrm{mL}^{-1}\right)$ were prepared by spiking $100 \mu \mathrm{L}$ of each working solution $\left(1,2,5,10\right.$ and $\left.20 \mu \mathrm{g} \mathrm{mL}^{-1}\right)$ into 
$100 \mu \mathrm{L}$ of blank plasma and $800 \mu \mathrm{L}$ of methanol. These standards were used to construct calibration curves for the quantification of Curcumin in rat plasma concentrations ranging from 100 to $2000 \mathrm{ng} \mathrm{mL}^{-1}$.

\section{Animalmodel}

The experiments were performed on adult male WistarBratislava albino rats (mean age 17 weeks), weighing 200-250 g. The animals were brought from the Animal Facility of "Iuliu Hațieganu" University of Medicine and Pharmacy to the Physiology Biobase about two weeks prior to the experiment for acclimatization. The animals were housed in cages at an average temperature of $22 \pm 2{ }^{\circ} \mathrm{C}$ and ca. $55 \%$ relative humidity, on a 12 hours light-dark cycle. The rats had free access to standard pellets as basal diet and water ad libitum, except for 12 hours of fasting before the experiment. $150 \mathrm{mg}$ of Curcumin (Abcam, BioZyme, Romania) was dissolved into carboxymethyl cellulose (CMC) $0.5 \%$ and then administered as oral suspension by gavage ( 150 $\mathrm{mg}$ Curcumin $\mathrm{kg}^{-1}$ rat weight). By injecting intramuscular (i.m.) Turpentine, $0.6 \mathrm{~mL} \mathrm{~kg}^{-1}$ body weight, in the right posterior thigh of the rat we performed an inflammation model of myositis.

\section{Experimental design}

The rats were randomly assigned to four groups $(n=4)$. Our study included three experimental groups and a control group. Group I received $0.5 \mathrm{~mL}$ Curcumin oral suspension by gavage (150 mg Curcumin $\mathrm{kg}^{-1}$ body weight) and blood sampling was performed at 15, 30, 60, 90, 120, 150 and $180 \mathrm{~min}$. Group II received the oral Curcumin suspension as prophylactic regimen and one hour later Turpentine was injected i.m., followed by blood sampling at the same time intervals. The rats in the third group (Group III-therapeutic regimen) received Turpentine i.m. and after 2 hours Curcumin by gavage, then blood sampling was performed as specified for the other two experimental groups. We have chosen the 2 hour post injury treatment model as we intended to explore not the immediate transient vascular response (lasting maximum 30 minutes), but the delayed inflammatory response (which starts from 2 hours and lasts up to 8 hours) of the vascular leakage. During the mentioned span of time chosen, cellular modifications occur, as in stasis blood leukocytes accumulate along the vascular endothelium. After the last blood sampling at 180 minutes the animals were sacrificed by cervical dislocation under general anaesthesia with a combination of Ketamine (i.p. $50 \mathrm{mg} \mathrm{kg}^{-1}$ body weight) and Xylazine (20 $\mathrm{mg} \mathrm{kg}^{-1}$ body weight). Tissue samples were collected from all the study groups from the liver, kidneys and muscles of the left posterior thigh.

\section{Ethical considerations}

The study protocol was approved by the Institutional Animal Ethical Committee (IAEC) of "Iuliu Hațieganu" University of Medicine and Pharmacy Cluj-Napoca (no 121/31.03.2014). Experiments were performed following the Animal Testing Regulations.

\section{Evaluation method of oxidative stress and antioxidant capacity Plasma sample preparation}

Blood (approx. $1 \mathrm{~mL}$ ) was collected from the rat retro orbital plexus in an EDTA test tube at 15, 30, 60, 90, 120, 150 and 180 min post dosing of Curcumin suspension. Immediately after collection, blood samples were gently inverted several times to ensure complete mixing with the EDTA solutions. The samples were left at room temperature for more than half an hour and then centrifuged at $4500 \mathrm{rpm}$ for 10 minutes. After centrifugation, the upper organic layer was aspirated with a pipette and inserted into a clean Eppendorf tube, resulting a quantity of $0.5 \mathrm{~mL}$ plasma (containing three types of proteins: albumins, globulins and fibrinogen).

\section{Tissue sample preparation}

In order to determine the total antioxidant capacity (by ABTS testing) and to perform histopathological assessment, samples were collected from the liver, kidneys and muscle of the left posterior thigh, contralateral to the Turpentine injection.

Tissue homogenization was performed using a Polytron homogenizer (Brinkman Kinematica, Lucern, Switzerland). The homogeneous medium was a $50 \mathrm{mM}$ Tris-buffered saline +10 mM EDTA with a pH of 7.5. A given volume of Tris-buffered saline was added to a tissue sample while stirring in ice bath. The content was centrifuged at $4{ }^{\circ} \mathrm{C}$ for ten minutes at $1000 \mathrm{x}$. The supernatant was then separated and its total protein content, expressed in milligrams of protein, was determined by using Bradford's method (Noble and Bailey, 2009).

\section{Determination of oxidative stress by $M D A$ assessment}

The determination of lipid peroxidation by fluorescence relies on the fact that produced MDA will react with the 2thiobarbituric acid to form a fluorescent adduct. The MDA was determined according to Conti method, with a Perkin Elmer spectrofluorimeter (by a synchronous technique with excitation at $534 \mathrm{~nm}$ and emission at $548 \mathrm{~nm}$ ) and expressed in $\mathrm{nmol} \mathrm{mg}^{-1}$ (Contietal., 1991).

\section{Determination of oxidative stress by $P C$ assessment}

The determination of carbonylated proteins represents an easy technique that quantifies the oxidative modifications of proteins. It relies on the reaction with a classic carbonyl reagent: 2,4-dinitrophenylhydrazine, leading to the formation of 2,4dinitrophenylhydrazone, a yellow compound that can be determined spectrophotometrically. Carbonylated proteins were assessed in serum samples using Reznick method and results expressed in nmol mg ${ }^{-1}$ protein (Reznick and Packer, 1994; Dimon-Gadal et al., 2000)

Determination of total antioxidant capacity (free radical scavenging activity) based on ABTS test

This method consists of decolouring a solution that contains radical cation $\mathrm{ABTS}^{+}$as a result of the action of some lipophilic or hydrophilic antioxidants, present in biological samples or plant extracts. This radical derives from ABTS reaction [2.2'azino-bis (3-etylbenzothiazoline-6-sulfonic acid)] with potassium peroxide. $10 \mu \mathrm{l}$ of the sample were added in $1 \mathrm{~mL}$ of blue-coloured solution of $\mathrm{ABTS}^{+}$and the extinction read at 734 $\mathrm{nm}$ after 5 minutes. The results were expressed in equivalents of Trolox ( $\mu \mathrm{M}) \mathrm{mg}^{-1}$ protein (Re et al., 1999).

\section{Preparation of samples for histopathological assessment}

For the histopathological evaluation the tissue biopsies were immediately fixed in $10 \%$ phosphate-buffered formalin (Chempur, Poland) for $24 \mathrm{~h}$, embedded in paraffin wax (Histowax, Histo-Lab. Ltd, Gothenburg, Sweden), cut into 3-5 $\mu \mathrm{m}$ sections and stained with haematoxylin and eosin (HE). 


\section{Statistical analysis}

To evaluate systemic and local oxidative stress and total antioxidant capacity, a comparative statistic test was used for two independent groups T-test (Student) considering a significant $\mathrm{p}$ $<0,05$. For HPLC analysis, Kruskal-Wallis and Mood's Median test were used to compare medians of populations (samples) whose distribution had the same shape and equal variance. The analysis was achieved with SPSS (Statistical Package for the Social Sciences16.0 for Windows, SPSS Ins, SUA) and software R' (R Development, 2010).

\section{Results}

The organ sampling procedure (for liver and kidneys) required the opening of the abdominal cavity and the exposure of the stomach and intestines. At three hours after oral Curcumin administration, the macroscopic aspect of the stomach, with two thirds coloured in yellow, indicated the presence of Curcumin in the animal's stomach (Fig. 1).

\section{Histopathological assessment of the samples}

The biopsies from the left thigh of the experimental animals showed normal morphologic aspects of skeletal muscle fibers in cross section with polygonal shaped muscle cells, hyperchromatic nuclei at the periphery of each cell, without inflammatory infiltrate at the level of endomysium or perimysium (Fig. 2).

The hepatic biopsies from the experimental animals showed a normal hepatic parenchyma with cords of hepatocytes heading towards the centro-lobular vein, with almost 25\% binucleated cells, with congestion of sinusoidal capillaries in Groups II and III, without inflammatory infiltrate in the intralobular reticular stroma and perilobular spaces (Fig. 3).

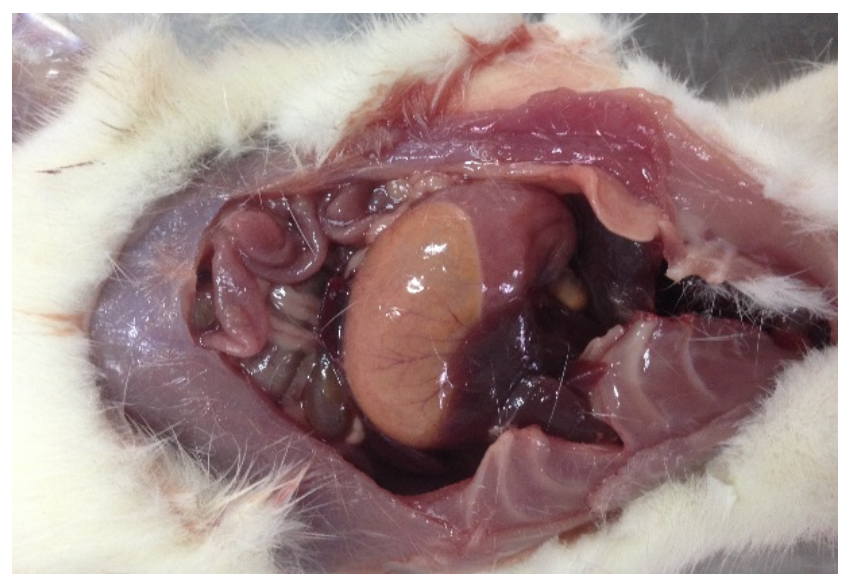

Fig. 1. Abdominal content of the rat at 3 hours after the oral treatment with Curcumin suspension
The biopsy taken from the kidney parenchyma showed normal morphology for Malpighian renal corpuscles and tubular structures of the nephron and collecting tubules, with a small amount of interstitial inflammatory infiltrate and pale areas representing artefacts (Fig. 4).

Evaluation of oxidative stress levels by serum $M D A$ (malondialdebide) and PC (carbonylated proteins) assessment from the experimental groups

Rats from Group I (Curcumin only) had lower serum MDA values compared to animals from Control group. The presence of inflammation in Group II (Curcumin + Turpentine at $1 \mathrm{~h}$ ) and Group III (Turpentine + Curcumin at $2 \mathrm{~h}$ ) increased the oxidative stress level investigated by mean serum MDA from $15 \mathrm{~min}$ up to $3 \mathrm{~h}$ samples. The mean MDA values were significantly increased in Group II ( $p=0.0004$ as compared to Control; $\mathrm{p}=0.0001$ as compared to Group I). The highest mean of serum MDA was detected in Group III and was significantly increased when compared to Group I $(\mathrm{p}=0.007)$ (Fig. 5).

The lowest mean serum PC value was detected in Group I (Curcumin only), while Groups II (Curcumin + Turpentine at $1 \mathrm{~h}$ ) and III (Turpentine + Curcumin at $2 \mathrm{~h}$ ) with induced inflammation, recorded higher values of oxidative stress than Control group, but the $\mathrm{p}$ values obtained were above the statistical border of 0.05 . The highest oxidative stress (measured by mean serum PC value) was identified in Group III, but it was not statistically significant when compared to the other study groups $(\mathrm{p}>0.05)$ (Fig. 6).

Group I recorded higher values of mean serum ABTS (reflecting the total antioxidant the Control group $(\mathrm{p}>0.05)$. The prophylactic regimen with Curcumin performed in Group II, had the lowest antioxidant value, significantly decreased by 4.94 (95\% CI 3.1-6.79) when compared to Group I ( $p=0.016)$ (Fig. 7). Groups II and III, in which acute inflammation was present, recorded lower values of serum ABTS than Control group, with $p>0.05$ in both cases. The therapeutic regimen with Curcumin (Group III) had lower values by 1.79 (95\% CI -0.29$3.87)$, but not statistically significant $(\mathrm{p}>0.05)$ when compared to Group I (Fig. 7).

Evaluation of the antioxidant capacity of Curcumin by ABTS assessment of muscle and internal organ (liver, kidney) tissues

All study groups had lower liver ABTS values than Control Group. Prophylactic therapy with Curcumin in Group II recorded a significantly higher mean ABTS of liver tissue by 0.15 (95\% CI 0.12-0.19) than in Group I $(p=0.006)(p<0.05)$. Group III recorded higher liver ABTS values than Group I by 0.22 (95\% CI 0.17-0.27), the difference being significant as $\mathrm{p}=$ 0.004 ( $p<0.05)$. Both groups in which inflammation was induced developed a higher antioxidant capacity at hepatic level in the context of myositis (Table 1). Compared to the
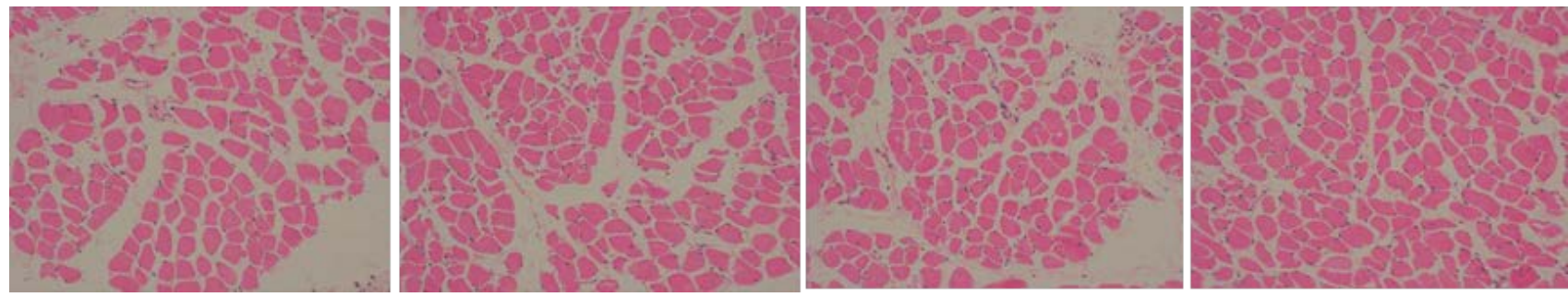

Fig. 2. Muscle tissue, cross section, $20 \times$, H.E. stain. From left to right: Control, Group I, II, III 

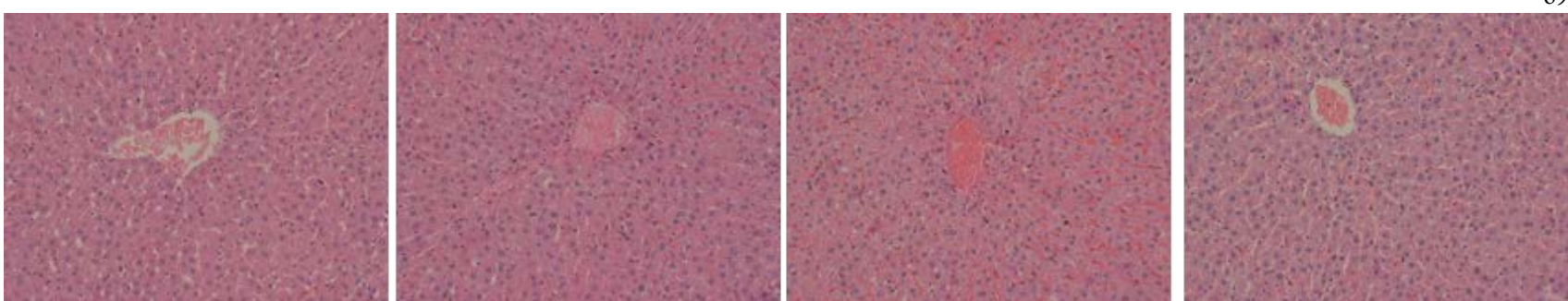

Fig. 3. Hepatic parenchyma, cross section with centro-lobular vein, 20 x, H.E. stain. From left to right: Control, Group I, II, III
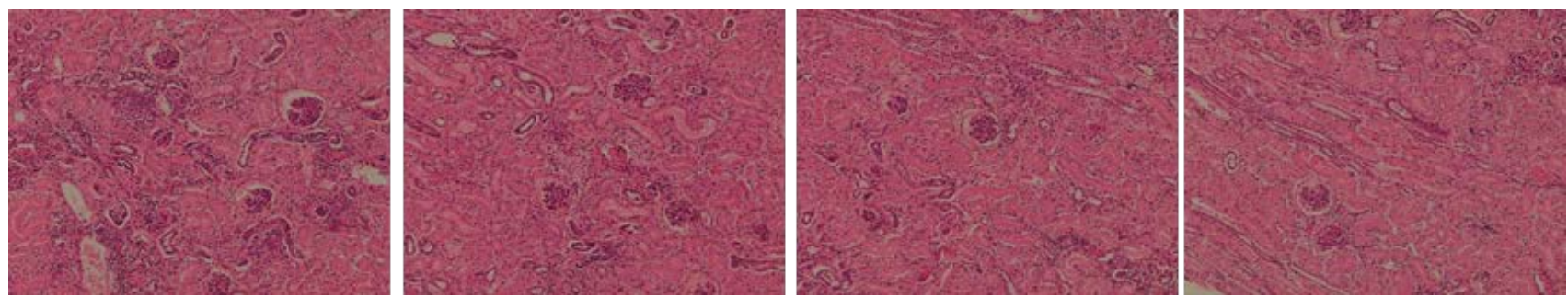

Fig. 4. Renal parenchyma, 10 x, H.E. stain. From left to right: Control, Group I, II, III

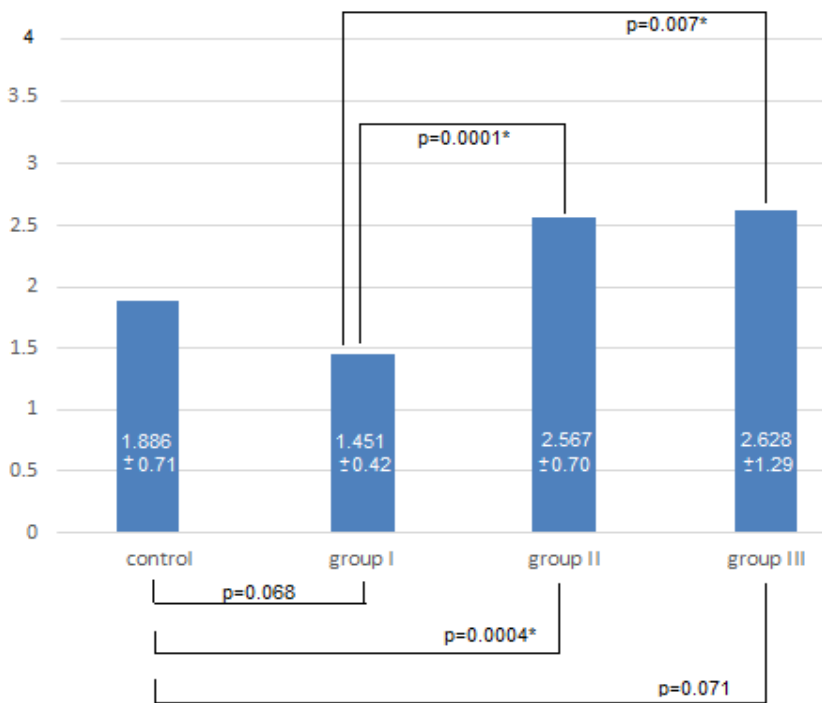

Fig. 5. Serum MDA (nmol mg-1 protein) results in: Control, Group I (Curcumin only), Groups II (Curcumin + Turpentine at $1 \mathrm{~h}$ ) and Group III (Turpentine + Curcumin at $2 \mathrm{~h})$. Data are presented as mean value \pm standard deviation from 15 min to $3 \mathrm{~h}$ samples. ${ }^{*}$ Statistically significant

prophylactic regimen (Group II) the therapeutic regimen (Group III) had higher mean ABTS liver values, but not statistically significant as $\mathrm{p}=0.053$.

Mean ABTS in kidney tissue did not record significant differences between study Groups I and II, as $\mathrm{p}=0.859$. Group I had significantly higher values than Group III by 0.24 (95\% CI $0.17-0.31)$, as $\mathrm{p}=0.007$ ( $\mathrm{p}<0.05)$. Both prophylactic and therapeutic regimens had lower ABTS mean values than Group I and Control (Table 1).

In muscle tissue (posterior left thigh) ABTS values were lower in the study groups with induced inflammation compared to Control and Group I. Mean muscle ABTS levels were statistically higher in Group I by 0.22 than those in Group II, $p=$ $0.004(p<0.05)$ and by 0.11 than those in Group III, $p=0.003$ $(\mathrm{p}<0.05)$ (Table 1). The therapeutic regimen (Group III) recorded higher values than the prophylactic regimen (Group II), but not statistically significant $(\mathrm{p}>0.05)$.

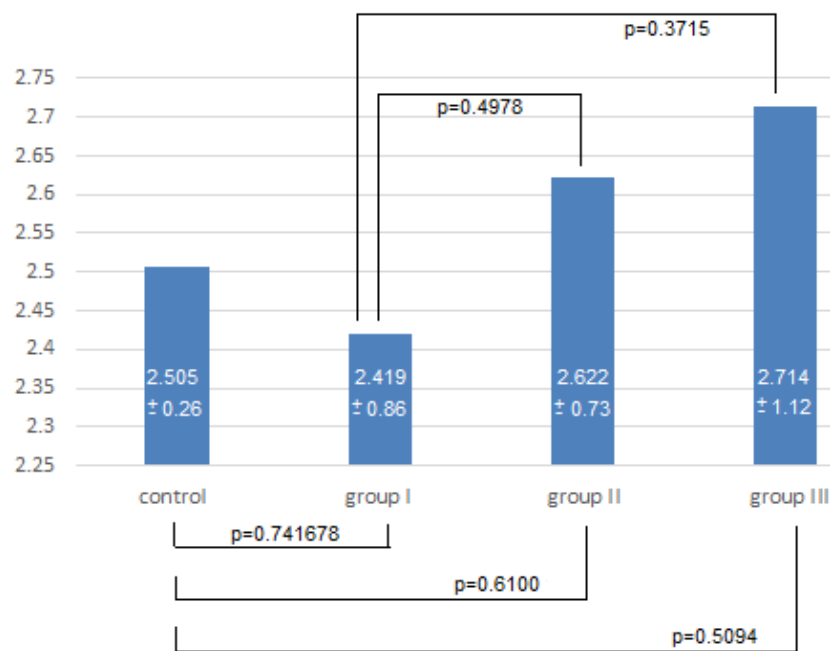

Fig. 6. Serum PC (nmol $\mathrm{mg}^{-1}$ protein) results in: Control, Group I (Curcumin only), Groups II (Curcumin + Turpentine at $1 \mathrm{~h}$ ) and Group III (Turpentine + Curcumin at $2 \mathrm{~h}$ ). Data are presented as mean value \pm standard deviation from 15 min to $3 \mathrm{~h}$ samples. ${ }^{*}$ Statistically significant

\section{Determination of Curcumin concentration by HPLC analysis}

HPLC analysis illustrates Curcumin as a peak at the retention time of $2.89 \mathrm{~min}$. Curcumin concentration was the highest in Group I (Curcumin only) and the lowest in Group III (the therapeutic regimen) at 15 minutes sampling (Fig. 8). Both groups in which inflammation was induced (Groups II and III) recorded lower Curcumin concentration in all analyzed samples (15-30-60-90-120-150-180 minutes). The signal which appears in the chromatogram before Curcumin represents the waste, belonging to proteins from plasma (Fig. 8). Waste is defined as everything out of interest separated from the sample before or in the course of the analysis.

The HPLC results displayed the highest concentration of Curcumin in Group I in all the sampling specified time intervals compared to Groups II and III. The maximum quantity of Curcumin in plasma is found in Group I at 15 minutes (128 ng $\left.\mathrm{mL}^{-1}\right)$ and in the rest of the groups at 30 minutes sampling: Group II (74 $\left.\mathrm{ng} \mathrm{mL}^{-1}\right)$, Group III $\left(57 \mathrm{ng} \mathrm{mL}^{-1}\right)$. After that peak, 
Table 1. Results of ABTS test ( $\mu \mathrm{M}$ Trolox) reflecting the antioxidant capacity of Curcumin in several types of tissue (liver, kidney and left posterior thigh muscle), from animals in Group I, II and III. Data are presented as mean value \pm standard deviation from 15 min to $3 \mathrm{~h}$ samples. ${ }^{*}$ Statistically significant $(\mathrm{p}<0.05$ compared to Group I)

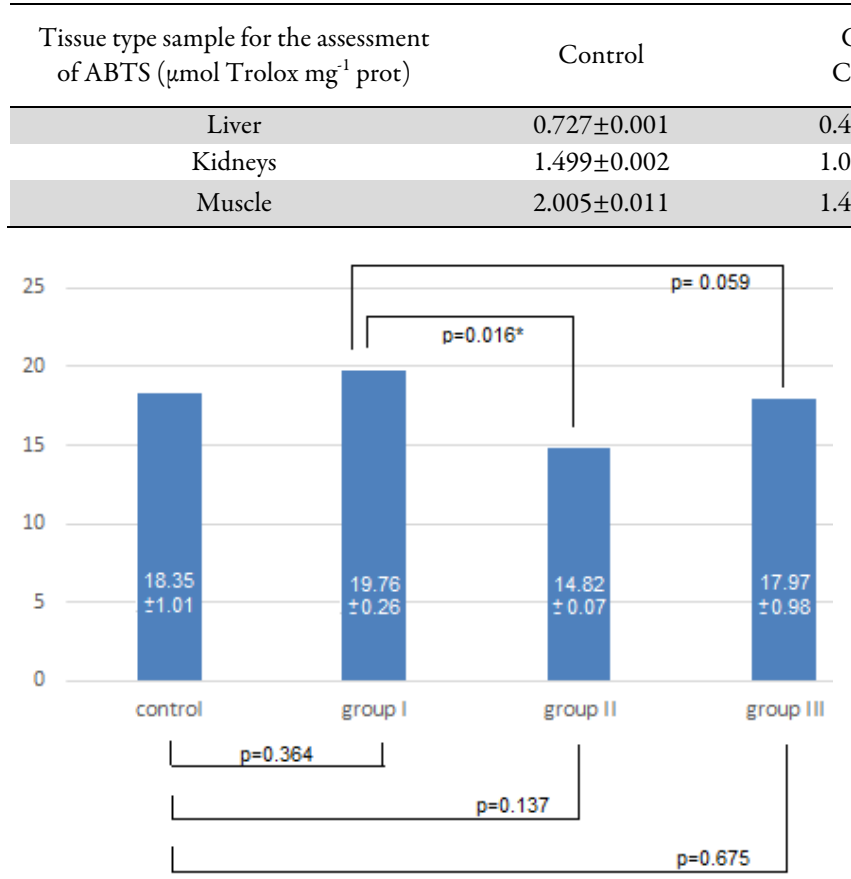

Fig. 7. Serum ABTS ( $\mu$ M Trolox) results in: Control, Group I (Curcumin only), Groups II (Curcumin + Turpentine at $1 \mathrm{~h}$ ) and Group III (Turpentine + Curcumin at $2 \mathrm{~h}$ ). Data are presented as mean value \pm standard deviation from 15 min to 3 h samples. * Statistically significant
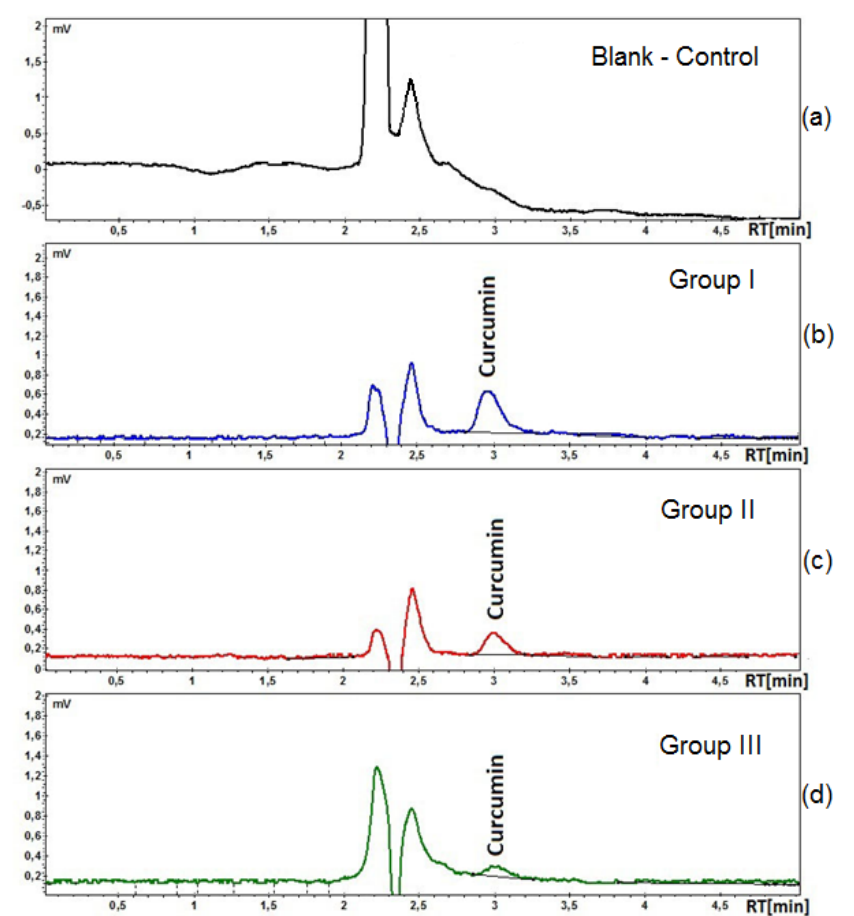

Fig. 8. Chromatograms of rat plasma at 15 minutes sampling from animals belonging to (a). Control Group; (b). Group I (Curcumin oral suspension of $150 \mathrm{mg}$ Curcumin $\mathrm{kg}^{-1}$ body weight) (c). Group II (Curcumin + Turpentine at $1 \mathrm{~h})$ (d). Group III (Turpentine + Curcumin at $2 \mathrm{~h}$ )

\begin{tabular}{ccc}
$\begin{array}{c}\text { Group I: } \\
\text { Curcumin }\end{array}$ & $\begin{array}{c}\text { Group II: Curcumin }+ \\
\text { Turpentine at } 1 \mathrm{~h}\end{array}$ & $\begin{array}{c}\text { Group III: Turpentine }+ \\
\text { Curcumin at } 2 \mathrm{~h}\end{array}$ \\
\hline $426 \pm 0.008$ & $0.581 \pm 0.004^{*}$ & $0.642 \pm 0.012^{*}$ \\
$.034 \pm 0.011$ & $1.031 \pm 0.01$ & $0.794 \pm 0.017^{*}$ \\
$.417 \pm 0.006$ & $1.19 \pm 0.006^{*}$ & $1.297 \pm 0.006^{*}$ \\
\hline
\end{tabular}

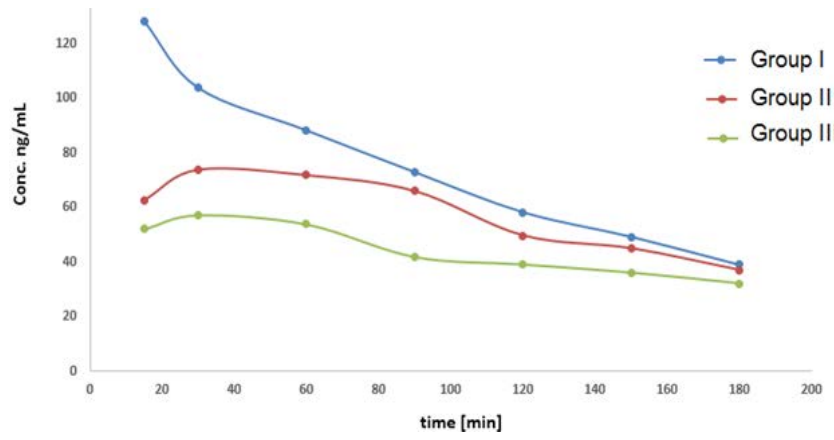

Fig. 9. Mean Curcumin concentration-time profiles by HPLC analysis in plasma samples for study Group I (Curcumin only), Group II (Curcumin + Turpentine at $1 \mathrm{~h}$ ) and Group III (Turpentine + Curcumin at $2 \mathrm{~h}$ ) at different time sampling intervals: $15-30-60-90-120-150-180$ minutes

Curcumin concentration decreased in a time-dependent manner in all study groups (Fig. 9).

The mean value of the three HPLC determinations was calculated for each sample-time frame and used as a mean score for statistical interpretation with nonparametric tests. We applied the Kruskal-Wallis test and the Mood's median in order to find out if the type of treatment applied to each group, influenced the evolution of Curcumin HPLC concentration in a significant way .

Both tests pointed out no statistically significant difference of mean values between the three study groups for each timeframe determination $(\mathrm{Sig}>0.05)$ (Table 2). The results did not certify a significant influence of the treatment upon the Curcumin concentration in the studied groups.

\section{Discussion}

Muscle tissue from the left thigh presented normal histopathologic aspect in all study groups, while the liver tissue in groups II and III presented slight congestion and the kidney samples had a small amount of interstitial inflammatory infiltrate in all study groups. The modifications observed are not related to the acute induced inflammation model or to the applied treatment.

Free radicals usually attack several cell components, such as the polyunsaturated fatty acid (PUFA), deoxyribonucleic acid (DNA) and proteins (Schaffer et al., 2015). An increase in free radicals causes overproduction of Malondialdehyde (MDA), a final product of polyunsaturated fatty acids peroxidation in cells (Ewing et al., 2007). Free radicals generate the lipid peroxidation process in an organism by damaging the lipid membrane. Lipid peroxidation is, actually, the most popular biomarker of oxidative stress, commonly assessed by MDA determination (Ghosh et al., 2015; Gawel et al., 2004). 
Table 2. Kruskal-Wallis Test statistics for HPLC results with the type of treatment (Group) as grouping variable ( $\mathrm{df}=$ degrees of freedom; asymp. sig. $=$ the statistical significance of the test)

\begin{tabular}{|c|c|c|c|c|c|c|c|}
\hline & $15 \mathrm{~min}$ & $30 \mathrm{~min}$ & $60 \mathrm{~min}$ & $90 \mathrm{~min}$ & $120 \mathrm{~min}$ & $150 \mathrm{~min}$ & $180 \mathrm{~min}$ \\
\hline Chi-Square & 4.571 & 2.0 & 1.143 & 2.571 & 3.714 & 4.571 & 4.571 \\
\hline $\mathrm{df}$ & 2 & 2 & 2 & 2 & 2 & 2 & 2 \\
\hline Asymp. Sig. & 0.102 & 0.368 & 0.565 & 0.276 & 0.156 & 0.102 & 0.102 \\
\hline
\end{tabular}

This study results reflect a higher oxidative stress level (measured by MDA) in groups where acute inflammation was induced by turpentine oil injection: Groups II (Curcumin + Turpentine at $1 \mathrm{~h}$ ) and III (Turpentine + Curcumin at $2 \mathrm{~h}$ ) with a statistically significant difference for serum MDA levels compared to Group I (Curcumin only). The comparative assessment between Group I and Control showed that Curcumin administration decreased oxidative stress by lowering the serum $A B T S$ value. The values obtained validated the antioxidant effect of the tested substance (Curcumin) and are in agreement with previously published results (Gupta et al., 2009; Sharma et al., 2010; Sahin-Kavakli et al., 2011; Savcum et al., 2013; Hussein et al., 2014; Hismiogullari et al., 2014).

Oxidative decomposition of the polyunsaturated fatty acids initiates chain reactions that lead to the formation of a variety of carbonyl species (Suzuki et al., 2010). Research performed in redox proteomics and mass spectrometry identified carbonylated proteins during various disease states, including inflammation. Oxidative stress, often metal catalysed, leads to protein carbonylation, a type of protein oxidation promoted by reactive oxygen species (Donne et al., 2006). During this process, the native amino acids side chains in proteins are modified to carbonyl (aldehyde and ketone) derivatives (Stadtman and Levine, 2006).

Increased PC values were detected in Groups II and III where inflammation was induced, but the difference of serum PC means was not statistically significant $(\mathrm{p}>0.05)$ when compared to Group I. Curcumin administration in Group I led to the decrease of PC value, certifying the reduction of oxidative stress after this oral drug supplementation.

Multiple methods have been developed to measure total antioxidant capacity (TAC), as assessment marker of the antioxidant status: oxygen radical absorbance capacity (ORAC), ferric reducing ability of plasma (FRAP), total radical trapping antioxidant potential (TRAP) and Trolox equivalent antioxidant capacity (TEAC) (Antolovich et al., 2002). Trolox equivalent performed with the ABTS solution represents an important screening tool for oxidative stressrelated diseases by monitoring plasma TAC (Kambayashi et al., 2009).

The serum ABTS levels compared to Control group were increased in Group I, treated with Curcumin only and decreased in the presence of acute inflammation in Groups II and III. These results suggested that the balance between the oxidative and antioxidant systems in rats was disturbed during the presence of inflammation, even under Curcumin treatment.

Other studies, focused on the biochemical effects of inflammation and induced toxicity in rats, showed an increase in serum MDA and serum NO (nitric oxide) as well as a reduction in the antioxidant parameters: SOD (superoxide dismutase), CAT (catalase), GSH (glutathione) and TAC in both serum and hepatic tissue (Abdel-Daim and Abdou, 2015).

The liver is the main detoxifying organ, it metabolizes various compounds that produce free radicals (FR). Although the liver maintains metabolic homeostasis, its oxidativeantioxidative balance can be disrupted, leading to the state of oxidative stress, deleterious processes and possible liver disease. Antioxidants scavenge the free radical and maintain the oxidative-antioxidative balance in the liver (Casas-Grajales and Muriel, 2015).

Curcumin has tremendous therapeutic potency as an antiinflammatory, antioxidant and anti-microbial agent. Several studies reported that Curcumin has a significant hepatoprotective activity by lowering the levels of serum marker enzymes and lipid peroxidation. Curcumin may act by detoxifying enzymes which inhibit ROS, following administration of toxicants (Lam et al., 2015).

Treatment with Curcumin significantly increased TAC level in a dose dependent manner on a rat inflammation model. Higher liver TAC values were reported in a post-treatment group (stress induced for 60 days, then Curcumin administration for 30 days) than those in a pre-treatment group (Curcumin for 15 days prior to induced stress), even higher than in the Control group (Al-Rubaei et al., 2014).

In this study, liver TAC values were significantly increased in Groups II and III (with induced inflammation) ( $p<0.05$ when compared to Group I) and lower than in Control group. According to previous literature reports, the liver TAC values were higher in the therapeutic regimen (Group III) compared to the prophylactic regimen (Group II). The mean ABTS liver difference between the mentioned groups was not statistically significant, maybe due to the small number of samples.

Biological markers of oxidative stress were found elevated in inflammatory diseases, in which modifications of kidney structure and function are present (Yan et al., 2015).

In an acute kidney injury model, oral administration of Curcumin $\left(200 \mathrm{mg} \mathrm{kg}^{-1}\right.$ per day for a week) significantly increased MDA concentration, nitric oxide and carbonylated proteins content in the rat kidney with bilateral renal ischemia, followed by reperfusion (Waly et al., 2011). On the other hand, Curcumin administration improved renal function on mice models (evaluated by blood urea nitrogen and albuminuria), which was associated with a decrease in inflammatory markers and matrix proteins (Trujullo et al., 2013). Curcumin significantly improved oxidative stress by reducing TAC and GSH levels, as well as inhibiting the activity of CAT, GPX enzymes and SOD in human embryonic kidney cells (Waly et al., 2011).

Similar to previous literature reports, our findings underline a decrease of TAC in kidneys from animals with induced acute inflammation (Groups II and III). The therapeutic regimen with Curcumin (Group III) had significantly lower kidney mean TAC values $(\mathrm{p}<0.05$ when compared to Group I).

The experimental design of this study included the development of myositis (muscle inflammation) which can be produced by various factors, such as an infection, injury, certain medicines, exercise and chronic or autoimmune disease. The 
increased breakdown of muscle proteins, in particular the myofibrillar proteins actin and myosin, is a common metabolic consequence of the above mentioned diseases, resulting in muscle wasting, weakness and fatigue (Poylin et al., 2008; Li et al., 2009). Among muscle wasting-related transcription factors, $\mathrm{NF}-\mathrm{kB}$ (nuclear factor-kappaB) has been lately of study interest (Aggarwal and Sung, 2009).

The anti-inflammatory properties of Curcumin are, at least in part, due to the inhibition of NF-kB (Montiel-Duarte $e t$ al., 2004; Amani et al., 2010). Curcumin is believed to reduce the inflammation caused by myositis, decreasing the amounts of nitric oxide synthase (iNOS), COX-2 (cyclooxygenase) and LOX (lipoxygenase), phospholipase, leukotrienes, thromboxane, prostaglandins, collagenase, elastase, hyaluronidase, monocyte chemoattractant protein-1 (MCP-1), interferon-inducible protein, tumor necrosis factor (TNF) and interleukin 12 (Il-12), that trigger inflammation (Gutierres et al., 2015). Scientists also consider that the drug inhibits production of inflammatory cytokines by peripheral blood monocytes and alveolar macrophages and prevents the platelets from sticking together and producing blood clots (Sharma et al., 2007). Recent Curcumin studies described its role in blocking inflammatory pathways by effectively preventing the launch of proteins that trigger swelling and pain. Curcumin was the treatment which prevented protein degradation (Wyke et al., 2004), loss of muscle weight and muscle protein caused by injection of lipopolysaccharide (Jin and Li, 2007).

Turpentine intramuscular injection delivered in the right thigh of the rats from Groups II and III produced myositis, enhancing the level of oxidative stress. Curcumin administration in the same groups significantly decreased TAC levels, when compared to Control group $(p<0.05)$ validating the anti-inflammatory effect of the drug. The prophylactic Curcumin regimen (Group II) had a lower statistically significant muscle TAC value than the therapeutic regimen (Group III). Previous studies on other models of inflammation (murine colitis) reported the preventive and therapeutic effects of Curcumin (Jiang et al., 2006; Jian et al., 2005; Arafa et al., 2009). Research performed on human subjects concluded that short-term supplementation with bioavailable Curcumin significantly improves the inflammatory and oxidative status of patients, suggesting the benefits of prophylactic administration, with no toxicity risk (Menon and Sudheer, 2007).

\section{Conclusions}

This study results show a disrupted pro-oxidantantioxidant balance in the Turpentine induced inflammation model. The biochemical effects of inflammation in Groups II and III consisted of an increased peroxidation with elevated oxidative stress markers, as well as a reduced total antioxidant capacity in serum and tissues (kidney and muscle). The HPLC results displayed the highest concentration of Curcumin in Group I in all the sampling specified time intervals compared to the prophylactic (Group II) or the therapeutic regimen (Group III). This study underlines the ability of Curcumin, in the studied dose of $150 \mathrm{mg} \mathrm{kg}^{-1}$ body weight, as therapeutic and protective agent against tissue damage from oxidative stress in the acute inflammation model.

\section{Acknowledgements}

This paper was published under the frame financed by the "Iuliu Hațieganu" University of Medicine and Pharmacy ClujNapoca, internal grant no. 1491/14/28.01.2014.

\section{References}

Abdel-Daim MM, Abdou RH (2015). Protective effects of daily sulfide and Curcumin separately against thallium-induced toxicity in rats. Cell Journal 17(2):379-388.

Aggarwall BB, Sundaram C, Malani N, Ichkawa H (2007). Curcumin: the Indian solid gold. Advances in Experimental Medicine and Biology 595:1-75.

Aggarwal BB, Sung B (2009). Pharmacological basis for the role of curcumin in chronic diseases: an age-old spice with modern targets. Trends in Pharmacological Sciences 30(2):85-94.

Al-RubaeiZM, Mohammad TU, Ali LK(2014). Effects of local Curcumin on oxidative stress and total antioxidant capacity in vivo study. Pakistan Journal of Biological Sciences 17(12):1237-1241.

Amani AR, Somchit MN, Konting MM, Kok LY (2010). Vitamin E and Curcumin Intervention on lipid-peroxidation and antioxidant defense system. Journal of American Science 6(3):52-62.

Anand P, Kunnumakkara AB, Newman RA, Aggarwal BB (2007). Bioavailability of Curcumin: problems and promises. Molecular Pharmaceutics 4(6):807-818

Antolovich M, Prenzler PD, Patsalides E, McDonald S, Robards K (2002). Methods for testing antioxidant activity. The Analyst 127:183-198.

Arafa HM, Hemeida RA, El-Bahrawy AI, Hamada FM (2009). Prophylactic role of curcumin in dextran sulfate sodium (DSS)-induced ulcerative colitis murine model. Food and Chemical Toxicology 1:13111317.

Boyanapalli SS, Tony Kong AN (2015). Curcumin, the king of spices: epigenetic regulatory mechanisms in the Prevention of Cancer, Neurological and Inflammatory Diseases. Current Pharmacology Reports 1(2):129-139.

Casas-Grajales S, Muriel P (2015). Antioxidants in liver health. World Journal of Gastrointestinal Pharmacology and Therapeutics 6(3):59-72.

Conti M, Morand PC, Levillain P, Lemonnier A (1991). Improved fluorometric determination of malonaldehyde. Clinical Chemistry 37(7):1273-1275.

Deguci A (2015). Curcumin targets in inflammation and cancer. Endocrine metabolic and immune Disorders-Drug Targets 15(2):88-96.

Dimon-Gadal S, Gerbaud P, Therond P, Guibourdenche J, Anderson WB, Evain-Brion D, Raynaud F (2000). Increased oxidative damage to fibroblasts in skin with and without lesions in psoriasis. Journal of Investigative Dermatology 114:984-92.

Donne D, Aldini I, Carini G, Colombo M, Rossi R, Milzani R (2006). Protein carbonylation, cellular dysfunction, and disease progression. Journal of Cellular and Molecular Medicine 10(2):389-406.

Ewing SA, Krieg T, Davidson JM (2007). Inflammation in wound repair: molecular and cellular mechanisms. Journal of Investigative Dermatology 127(3):514525.

Gawel S, Wardas M, Niedworok E, Wardas P (2004). Malondialdehyde (MDA) as a lipid peroxidation marker. Wiad Lek 57(9-10):453-5. 
Ghosh S, Banerjee S, Sil PC(2015). The beneficial role of curcumin on inflammation, diabetes and neurodegenerative disease: a recent update Food Chemical Toxicology 83:111-124.

Goes A, Kunnumakkara AB, Aggarwal BB (2008). Curcumin as "Curecumin": From kitchen to clinic. Biochemical Pharmacology 75(4):787-809.

Gupta YK, Briyal S, Sharma M (2009). Protective effect of Curcumin against kainic acid induced seizures and oxidative stress in rats. Indian Journal of Physiology and Pharmacology 53(1):39-46.

Gupta SC, Patchva S, Aggarwal BB (2013). Therapeutic Roles of Curcumin: Lessons Learned from Clinical Trials. The AAPS Journal 15(1):195-218.

Gutierres VO, Campos ML, Arcaro C, Assis RP, Baldan-Cimatti HM, Peccinini RG, Brunetti S (2015). Curcumin Pharmacokinetic and Pharmacodynamic Evidences in Streptozotocin-Diabetic Rats Support the Antidiabetic Activity to Be via Metabolite(s). Evidence-Based Complementary and Alternative Medicine http://dx.doi.org/ $10.1155 / 2015 / 678218$.

Hismiogullari SE, Hismiogullari AA, Sunat FB (2014). The protective effect of Curcumin on carbon tetrachloride induced liver damage. Revue de Médicine Vétérinaire 165(7):194200.

Hsu CH, Cheng AL (2007). Clinical studies with Curcumin. Advances in Experimental Medicine and Biology 595:471-480.

Hussein A, El-Said Azab M, El-Shall K (2014). Protective Effect of Curcumin on Antioxidant Defense System and Oxidative Stress in Liver Tissue of Iron Overloading Rats. Asian Journal of Clinical Nutrition 6:1-17.

Jagannathan L, Cuddapah S, Costa M (2016). Oxidative stress under ambient and physiological oxygen tension in tissue culture. Current Pharmacology Reports 2(2):6472.

Jian YT, Mai GF, Wang JD, Zhan YL, Luo RC, Fang YX (2005). Preventive and therapeutic effects of NF-kappaB inhibitor curcumin in rats colitis induced by trinitrobenzene sulfonic acid. World Journal of Gastroenterology 11:1747-1752.

Jiang H, Deng CS, Zhang M, Xia J (2006). Curcumin-attenuated trinitrobenzene sulphonic acid induces chronic colitis by inhibiting expression of cyclooxygenase-2. World Journal of Gastroenterology 12(1):3848-3853.

Jin B, Li YP (2007). Curcumin prevents lipopolysaccharide-induced atrogin1/MAFbx upregulation and muscle mass loss. Journal of Cellular Biochemistry 100(4):960-969.

Kambayashi Y, Binh NT, Asakura HW (2009). Efficient assay for total oxidant capacity in human plasma using a 96-well microplate. Journal of Clinical Biochemistry and Nutrition 44:46-51.

Lam P, Cheung F, Tan HY, Wang N, Yuen MF, Feng Y (2015). Hepatoprotective effects of Chinese medicinal herbs: a focus on antiinflammatory and anti-oxidatove activities. International Journal of MolecularScience 17(4):1-37.

Li J, Jiang Y, Wen J, Fan G, Wu Y, Zhang C (2009). A rapid and simple HPLC method for the determination of curcumin in rat plasma: assay development, validation and application to a pharmacokinetic study of curcumin liposome. Biomedical Chromatography 23(11):1201-1214.

Menon VP, Sudheer AR (2007). Antioxidant and anti-inflammatory properties of curcumin. Advances in Experimental Medicine and
Biology 595:105-125.

Mitchell RN (2013). Inflammation and Repair. In: Kumar V, Abbas AK, Aster JC (Eds). Robbinson Basic Pathology (9th Ed). Elsevier Saunders, Philadelphiapp 29-75.

Montiel-Duarte C, Ansorena E, López-Zabalza MJ, Cenarruzabeitia E, Iraburu MJ (2004). Role of reactive oxygen species, glutathione and NF$\kappa \mathrm{B}$ in apoptosis induced by 3.4 methylenedioxymethamphetamine ("Ecstasy") on hepatic stellate cells. Biochemical Pharmacology 67(6):1025-1033.

Mulay SR, Holderied A, Kumar SV, Anders HJ (2016). Targeting inflammation in so-called acute kidney injury. Seminars in Nephrology 36(1):17-30.

Noble JE, Bailey MJA (2009). Quantitation of Protein. Methods in Enzymology 463:73-95.

Parakrama C, Clive RT (2005). Concise Pathology. McGraw-Hill (3rdEd), New York.

Perez IB, Brown PJ (2014). The role of ROS signaling in cross-tolerance: from model to crop. Frontiers in Plant Science 5:754756.

Porth C (2007). Essentials of pathophysiology: concepts of altered health states. Lippincott Williams \& Wilkins, Hagerstown.

Poylin V, Fareed M, O'Neal P, Alamdari N, Reilly N, Menconi M, Hasselgren P (2008). The NF- $\kappa$ B Inhibitor Curcumin Blocks SepsisInduced Muscle Proteolysis. Mediators of Inflammation http://dx.doi.org/10.1155/2008/317851.

R Development Core Team, R Foundation for Statistical Computing (2010). Vienna, Austria. Retrieved 2016 May 12 from http://www.Rproject.org.

ReR, Pellegrini N, ProteggenteA, Pannala A, YangM, Rice-Evans C (1999). Antioxidant activity applying an improved ABTS radical cation decolorization assay. Free Radical Biology and Medicine 21:271-75.

Reznick AZ, Packer L (1994). Oxidative damage to proteins: Spectrophotometric method for protein carbonyl assay. Methods in Enzymology 233:357-361.

Sahin Kavakli H, Koca C, Alici O (2011). Antioxidant effects of Curcumin in spinal cord injury in rats. Ulus Travma Acil Cerrahi Derg 17(1):14 18.

Savcum GY, Ozkan E, Dulundu E (2013). Antioxidant and antiinflammatory effects of Curcumin against hepatorenal oxidative injury in an experimental sepsis model in rats. Ulus Travma Acil Cerr Derg 19(6):507-515.

Serhan CN, Savill J (2005). Resolution of inflammation: the beginning programs the end. Nature Immunology 6(12):1191-1197.

Sermon CN (2008). Controlling the resolution of acute inflammation: a new genus of dual anti-inflammatory and proresolving mediators. Journal of Periodontology 79(8):1520-1526.

Schaffer M, Schaffer PM, Bar-Sela G (2015). An update on Curcuma as a functional food in the control of cancer and inflammation. Current Opinion in Clinical Nutrition and Metabolic Care 18(6):605-611.

Sharma RA, Steward WP, Gescher AJ (2007). Pharmacokinetics and pharmacodynamics of curcumin. Advances in Experimental Medicine and Biology 595:453-470.

Sharma V, Nehru B, Munshi A, Jyothy A (2010). Antioxidant potential of Curcumin against oxidative insult induced by pentylenetetrazol in 
74

epileptic rats. Methods and Findings in Experimental Clinical Pharmacology 32(4):227-32.

Stadtman ER Levine RL (2006). Chemical modification of proteins by reactive oxygen species. In: Dalle-Donne I, Scaloni A, Butterfield DA (Eds) Redox Proteomics: From Protein Modifications to Cellular Dysfunction and Diseases. John Wiley \& Sons, Hoboken pp 3-23.

Suzuki YJ, Carini M, Butterfield DA (2010). Protein Carbonylation. Antioxidants and Redox Signaling 12(3):323-325.

Trujillo J, Chirino YI, Molina-Jijón E, Andérica-Romero AC, Tapia E, Pedraza-Chaverrí J (2013). Renoprotective effect of the antioxidant Curcumin: Recent findings. Redox Biology 1:448-456.
Waly MI, Al Moundhri MS, Ali BH (2011). Effect of Curcumin on Cisplatin- and Oxaliplatin-Induced Oxidative Stress in Human Embryonic Kidney (HEK) 293 Cells. Renal Failure Journal 33:518523.

Wyke SM, Russell ST, Tisdale MJ (2004). Induction of proteasome expression in skeletal muscle is attenuated by inhibitors of NF- $k \mathrm{~B}$ activation. British Journal of Cancer 91(9):1742-1750.

Yan H, Yuan Y, Xi Z, Kun Z, Shaohua C, Zhiyun D (2015). Curcumin, inflammation, and chronic diseases: how are they linked. Molecules 20:9183-9213. 